\title{
(Re)Ciphering Nations: Greece as a Constructed Illegibility in Odysseas Elytis's Poetry
}

\author{
Álvaro García Marín \\ Consejo Superior de Investigaciones Científicas, Madrid, Spain
}

\begin{abstract}
In their attempt to construct their identity in opposition to European one, non-Western new nations with alphabets such as Greek, Hebrew, or Cyrillic, used them as a way of emphasizing difference, and thus provide symbolic spaces for the newborn nations. The illegibility of these alphabets for Western people, along with the ancient prestige of at least Hebrew and Greek, fostered the illusion of temporal continuity and provided legitimacy to their atomization projects. Odysseas Elytis (1911-1996), Nobel Prize for Literature winner in 1979 and the last national poet of Greece, blends this old tendency in Greek culture and the broader claim of modern European poets for the essential autonomy of art and literature. His efforts to reinforce the walls separating Greece from Latin-Western culture by reinforcing the illegibility of both Greek and poetic idioms, aim at constructing a more essential Greece, founded on aesthetics, language, and writing instead of politics, institutions, or geographic borders. In this paper, engaging mainly in the fields of literary and postcolonial studies, the author intends to analyze the mechanisms by which language, writing, or literature can be used to (re)cipher once again the already exclusive concept of nation, and thus to undermine every possibility of deciphering and translatability. He concludes that in "conceptually colonized" nations such as Greece, this process implies and anticolonial movement still caught nevertheless in a colonial discursivity.
\end{abstract}

Keywords: Modern Greece, postcoloniality, writing, illegibility, poetry

\section{Introduction}

Most studies on Modern Greek literature overlook the peculiar position of Greece as a nation in modernity and the singular conditions of its production, coterminous with the construction of the notion of Western civilization. Subsequently, they approach its authors as simple, uncomplicated members of the allegedly unitary tradition of European literature. It is necessary, however, to account for the "colonial difference" (Mignolo, 2002) inherent in Modern Greek literature, and thus to address the specific mechanisms whereby authors relate their literary production to the question of nation building or engage directly with it through their work. Odysseas Elytis, arguably the last of a long series of Greek national poets, has been predominantly studied as a canonical European modernist writer, or as a geographically marginal surrealist who just happened to be Greek. A deeper analysis of his poetry reveals nonetheless the central involvement of his work with the colonial condition of Greece, and the attempt to counteract it through the possibilities of the poetic language.

Álvaro García Marín, Ph.D., Consejo Superior de Investigaciones Científicas. 


\section{Modern Greece as Colonial Nation}

\section{“Conceptual” Modes of Postcoloniality}

While Greece has never been under European colonial rule in the traditional political sense, scholarship in the last decades has considered it to be a postcolonial nation. Leaving aside its long experience under the premodern and precolonial Ottoman Empire, the reasons for this denomination have to be tracked in a conceptual rather than in a military or material realm. Some authors have talked about metaphoric (Gourgouris, 1996) or surrogate colonization, colonization of the mind (Fleming, 2000, p. 1221) ${ }^{1}$, or even imperialism of the imagination (Goldsworthy, 1998). It is undeniable that the process of configuration of the new Greek nation in the 18th and 19th centuries was mediated, and to a great extent fostered, by European notions and models. The Hellenic Ideal and the Philhellenic discourse associated to it, so important themselves for the constitution of Western modernity, played a crucial role in this mechanism. The projection of an enlightened or romantic European image of Ancient Greece on the incipient Greek nationalism, however, made the legitimization of the latter conditional on the acceptation by Greek-speaking peoples in the Ottoman Empire of Western cultural and intellectual patronage. And, at the same time, it provided the Greeks of the diaspora, eager to become the political elite of the new state, with a justification before the "civilized world" for their independentist project. Of course, this metaphoric colonization had also practical consequences analysable from the point of view of a more canonical colonialism: The power was immediately placed in the hands of Western-educated, urban classes coming from the European diaspora that easily became the national bourgeoisie, and economic and political dependence was guaranteed by the imposition of a Bavarian king, who brought with him a whole educational system based on the Hellenic Ideal (Calotychos, 2003, p. 49) ${ }^{2}$. Obviously, this worked to reinforce the Classical model for Modern Greece and subjected the metaphoric colonization to a sort of vicious circle of relentless self-reproduction.

\section{Self-colonization: Paradoxes of Identity, or Greek Nation (De)construction Across the Logic of the Sign}

But the application of a Philhellenist discourse on Modern Greece was not without conflicts and tensions. After all, despite the claims of ulterior Greek historiography, the inhabitants of Greek-speaking Ottoman

\footnotetext{
1 "To view the relationship between Western Europe and the Balkans as homologous to colonialism is an approach that, if used with reason (and if historicized), has validity and can be fruitful. In the case of 18th and 19th-century Greece, the argument for the link between European philhellenism and some sort of metaphoric or pseudo-imperialism has been voiced by a number of scholars. Olga Augustinos has demonstrated that Greek travel literature of the period is directly tied to Europe's claim on the ancient Greek past and shows that this claim 'made [Greece] seem closer to the West' and somehow under its control. Artemis Leontis notes that, while the 'Greeks, former subjects of a powerful Eastern Empire, may be said to have gained the status of modern independent nation-state without having passed through administrative colonialization by the West', it nevertheless 'could be argued that modern Greece endured a "colonialization of the mind", given that its system of education was imported directly from Germany'. I myself have argued elsewhere that in the case of Greece the mechanisms of romantic philhellenism and the cultivation of the belief in Greece as the fount of Western civilization functioned as the underpinnings for a sort of 'surrogate' colonialism, whereby Greece was brought into the intellectual and cultural penumbra of the West, particularly Britain and France".

2 "It is worth relating that, politically, nationalism in colonial contexts often created a state patronage that spawned an authoritarian clientelism placed in the hands of Western-educated, urban nationalists. Greece's transition from imperial Ottoman rule to nation-statism differs considerably from the transition of African nations from colonialism to state rule. But the decisive contribution of a Western-educated elite is common to both. In subaltern contexts, at the time of decolonization, this 'class' becomes the 'national bourgeoisie' that fashions 'national identities' 'by methods that [were unable to] break formally with the system of representation that offered them an episteme in the previous dispensations: a "national buffer" between the ruler and the ruled"” (Spivak).
} 
territories at the beginnings of the 19th century were completely unaware of who Achilles, Ulysses, or Homer were. European Philhellenes at the 18th century saw them in fact as the "dirty descendants" of Ancient Greeks, whose presence in the same land impeded the total appropriation of the Greek landscape as a symbolic capital (Gourgouris, 1996, p. 124). The ideal of Classical Hellenism collided thus with the reality of Ottoman subjects with oriental customs whose national identity was to be articulated rather on their Christian Orthodox faith than in their uncertain and distant Ancient Greek ancestry. The imposition of a Hellenic identity on these Ottoman peoples tried consequently to establish for them an ethical and aesthetical model in order to reinscribe them in the symbolic space of Europe, as well as to appropriate the new state for Western influence. If the Crusades of the religious Middle Ages had striven to recover for the Christian community one of the two symbolic origins of Europe, Jerusalem, the secularised post-Enlightenment world needed now to culturally possess the other one, Athens. For the Ottoman Greeks themselves, however, this ideal identity to which they had to accommodate represented both a source of anxiety (Calotychos, 2003, p. 50) ${ }^{3}$ and of schizophrenia. Its ubiquitous presence compelled them to produce themselves as the image (Gourgouris, 1996, p. 143) ${ }^{4}$ that Europe was keen on recovering after two thousand years and therefore to differ temporally and ontologically their very being. From this moment on, Greeks could only look at themselves through the eyes of Europeans (as cited in Calotychos, 2003 , pp. 49-50) ${ }^{5}$. They were at once construed as the representatives of the "cradle of Europe", and thus situated at its very core, and as the oriental Others that disturbed the Western repossession of its own origins. A process of displacement and spacing can therefore be appreciated in the very center of the configuration of Modern Greece, which emerges as a signifier whose signified seems impossible to attain: Neither historically nor geographically or ontologically can Greece once for all be defined (Calotychos, 2003, p. 37) ${ }^{6}$. It is at the same time anteriority and posteriority to Europe, inside and outside it, the origin of its civilization and the outcome of its more elaborate and contemporaneous conceptual productions, a normative model and a performative present, its oriental margin and its spiritual center. This paradoxical nature may well be the main feature of every nationalism, as Anderson (2000) has stated with reference to their usual simultaneous claims for temporal rupture and for historical continuity. Nevertheless, Greece seems to take this fact to the extreme insofar as it articulates itself on what could be called the logic of the sign. Modern Greece was not just produced on the dialectic of some binary oppositions, such as Western-Eastern or Byzantine-Classical, that have marked its whole development. It was generated instead on the edge of a constitutive disemia, as the American scholar Herzfeld (1987) has termed it (pp. 95-122). This implies in fact its construction on the very interstice between opposites (West-East, Europe-Asia, modernity-tradition, autochthonous-foreign, secularity-Orthodoxy), and therefore its undecidability. As a nation, then, Greece is not a narration or a novel, as Anderson has put it, but an inextricable play of signs that seems to respond rather to the Freudian concept of dream-work (Gourgouris, 1996, pp. 28-32). Indeed, its very modern emergence as a metaphoric colonial product started from the constellation of meanings and allusions unleashed

\footnotetext{
3 "For the Enlightenment Western concern for resuscitating dead white people through Classical Greeks obliged Modern Greeks to assume a 'white man's burden' of their own, the racial impurity of not living up to the West's image of them".

4 "'[Greece] was characterized from the start not merely with the usual production of self-images for internal consumption, but also with the grave task of producing the right set of images for export".

5 There seems to be a connection between this phenomenon and the "double consciousness" theorized by W. E. B. Du Bois for African Americans in the United States (Du Bois, 1903).

${ }^{6}$ Caught between a Western vision of the Classical Ideal and the impossibility of an unmediated Greek conception of self, the Greek is stranded in no-man's land.
} 
by a single word: $E \lambda \lambda \alpha \dot{\alpha} \delta \alpha$ (Ellada, that is, Hellas). Among the many words the Greeks used up to the 18th century

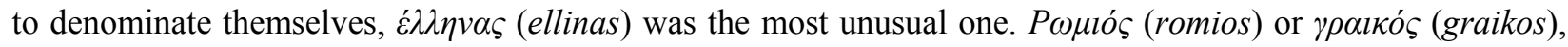
with obvious Latin and belated connotations, were far more popular, if not exclusive. The first colonial displacement took place therefore here, as the great mass of Greek-speaking Ottomans had to conform themselves to a term for which they were not originally the meaning and for which their time was not the time. The improper name $E \lambda \lambda \dot{\alpha} \delta \alpha$ was the price to pay for legitimizing Greek nationalism before the eyes of Europe, but at the same time it determined the condition of Greekness as the constatation of the impossibility of the proper name. The very process through which Greece is grafted onto a European genealogy or, even more, onto the prehistoric center of the European culture, foregrounds its otherness to the epistemological and rhetorical project of the Western modernity and the Enlightenment. Outside any possible closure of signification, Greece has to construct itself on what Homi Bhabha has called in-between spaces (Bhabha, 1990, p. 4) ${ }^{7}$. Signifieds become distant entities to which signifiers can only tend, without ever attaining them. They must also themselves be constructed as signifiers in a rather conscious process that reinforces Greek anxiety: Greeks can only conceive themselves as poor reflections of a more authentic self that they need to project before the Europeans' eyes in order to become someone, either the Ancient predecessor of classicism or the exotic Other of orientalism. Their colonial mimicry, then, looks not only onto the colonizer's identity, but also, and primarily, to an ideal, ahistorical and unattainable self. This responds to what Vangelis Calotychos (2003) has termed self-colonization (pp. 47-53), the assumption by Greeks that these imposed images are the real poles where their identity has to be negotiated. That is why the performative practice of Greece consists precisely of the deconstruction of the static and frozen signifieds that supposedly denote it—what Homi Bhabha has called "pedagogy" (Chrisman, 2004, p. $194)^{8}$-by means of a multiplication of signifiers that keep it on a constant negotiation and construction. Unable to meet its real essence, Greece reproduces itself in the insurmountable gap of this search. It becomes, like the derridean sign, the trace of a trace.

For all these reasons, from the beginning of its modern reformulation Greece needs to constantly rewrite itself and its own temporal, geographical, and metaphorical boundaries. It is in fact a process of infinite reinscriptions and erasures: Greece is reinscribed into the political and conceptual body of Europe as a liminal/central element, classical Hellenism is reinscribed into Modern Greece as an inside/outside limit that generates a temporal and semantic scission and erases its Byzantine and Ottoman history, and Byzantinism and

\footnotetext{
7 "The 'locality' of national culture is neither unified nor unitary in relation to itself, nor must it be seen simply as 'other' in relation to what is outside or beyond it. The boundary is Janus-faced and the problem of outside/inside must always itself be a process of hybridity, incorporating new 'people' in relation to the body politic, generating other sites of meaning and, inevitably, in the political process, producing unmanned sites of political antagonism and unpredictable forces for political representation. The address to nation as narration stresses the insistence of political power and cultural authority in what Derrida describes as the 'irreducible excess of the syntactic over the semantic'. What emerges as an effect of such 'incomplete signification' is a turning of boundaries and limits into the in-between spaces through which the meanings of cultural and political authority are negotiated".

8 "Bhabha classifies nationalism as a dominatory force that is expressed through the discursive mode of 'pedagogy'. Challenging it - through the contradictions of national 'discourse' itself-are the operations of the 'performative' mode. Thus 'the people' operate as performative subject and as pedagogical object of 'the nation', generating 'counter-narratives' that 'continually evoke and erase its totalizing boundaries'. The 'narrative' of the nation, that is, tends to self-deconstruction. What is significant, here, is the way that Bhabha's language casually characterizes nationalism as an essentializing, absolutist, and authoritarian power. Thus, the boundaries of the nation are referred to as 'totalizing', which is far from Anderson's nuanced account of the nation's boundaries as both open and closed, depending on whether linguistic, legal, cultural, or biological definitions of nationality are used". See also Bhabha (1994b).
} 
Orientalism are reinscribed into the Hellenic pole of the disemia attempting at the same time to erase and to correct the Classical Ideal. No chronological order can be found in this process. As the author have suggested above, Greece as a nation is not a legible narration, but an inextricable conglomerate of signs. Reinscriptions and rewriting not only can never stop, but constitute the very way Greece has to endlessly reproduce itself and thus to survive. Founded from the beginning on the exclusion and displacement of itself, insofar as Ottoman Greece is alienated by the European Hellenic Ideal, and the Hellenic Ideal is alienated in an oriental realm, the Greek nation needs to displace and retrace its inner and outer boundaries without end. Striving to become recognizable by Europeans, either as honourable descendants of Ancient Greeks or as oriental Others, Greeks find paradoxically their identity in their indecipherability by the West. Self-colonization becomes thus an unconscious anticolonial gesture. The European attempts to bring modern Greece into a classical (and Enlightenment) logic, according to which totalizing and self-contained concepts are possible, and meanings correspond univocally to transparent signifiers subject to perfect legibility (that is, the epistemological project of the Western modernity that underlies every project of colonial domination), are challenged by the very practice of the Greek nation.

\section{Odysseas Elytis: National Poetry as (Anti)Colonial (Re)Ciphering}

As long as signs and writing are so important for the configuration of Greece, it comes as no surprise that literature has been one of the crucial national institutions along its history. It has been there, even more than in politics or history itself, where national identity has been discussed, renegotiated, displaced, or reinscribed in creative ways ${ }^{9}$. The existence of national poets for this task until late in the 20th century, unlike most First World countries, attests as well to the postcolonial nature of Greece. Odysseas Elytis, Nobel Prize for Literature in 1979, was without any doubt the last of a long list of Greek national bards. Along his whole work he reflects, consciously or unconsciously, on what Greece really is. This implies, of course, reflecting also on the metaphorical colonialism of the West and on the disemia. In one of the fragments of his most famous poem, Axion Esti (1959), which consists of an account of the physical and textual elements that compose Greece, he mentions in a rather explicit way the action of Western colonizers in the 19th century:

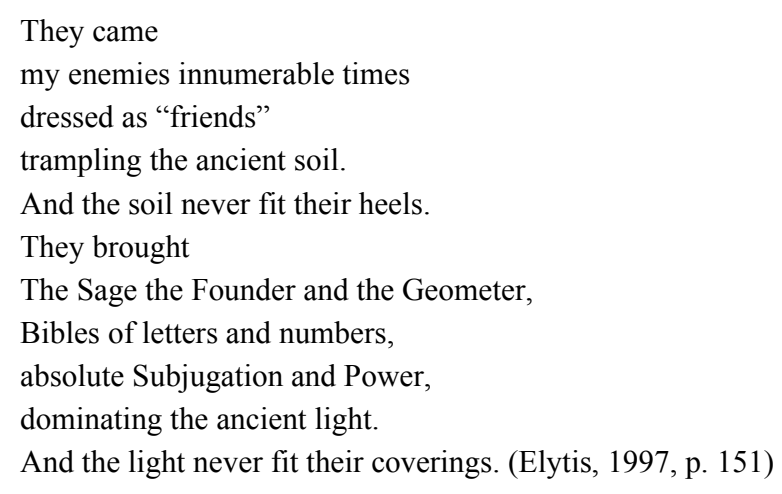

As we can see, the principal intention of Europeans is to apply to Greece the epistemology of Enlightenment and of technoscientific modernity, that is, the logic of a perfect semantic closure where every signifier accounts for a referent in reality, and where every object in the world can be known and described by language. Greece,

\footnotetext{
${ }^{9}$ See for this subject Lambropoulos (1987), and Jusdanis (1991).
} 
however, sets in motion its deconstructive power and impedes such a closure or adaptation. Western theories are unable to read Greek realities. Greece acts as a restance that undermines every attempt to totalize meaning. The Greek words can nevertheless find the way out this textual imperialism that tries to freeze Greece in static signifieds, as he says:

But with your word you lit

the lantern of the star in our hand, mouth of the innocent

portal of Paradise! (Elytis, 1997, p. 152)

Inasmuch as it consists of a symbolic and narrative construction, the making of a nation is always basically a process of ciphering rather than of deciphering: It tries to construct its own law, its own legibility, in order not to be legible by Others. The Others are not encompassed by its law, are not even legible by it, and nations define themselves precisely against this liminal point of indecipherability. This general process is reinforced in Greece, as we have already seen, by the very logic of its historical emergence. Elytis' endeavours to elucidate the "real face of Greece" (Elytis, 2000, p. 76) are based on an explicit rejection of the epistemology of Enlightenment and its understanding of Hellenism as a definable and legible historical, cultural, or geographical concept. Even more, Europe had constructed Greece as the source and prestigious genealogy of this very epistemological project of technoscientific modernity. To undo this process, he had only to thematize the mechanisms we have analyzed above: the construction of Greece on the interstice of spacing and on the logic of the sign, the insistence on difference rather than on identity, and the proliferation of signifiers as a manner of avoiding the fatal closure on a single signified. From this point of view, the nationalism of Elytis reciphers more and more the text of the Greek nation, in order to make it unreadable by the West. As he states in "Gift of a Silver Poem", the deciphering of the textuality of Greekness can only be made by foreign powers, and equates to its disappearing, while restoring its symbolic and imaginal conglomerate not only resuscitates it, but constitutes also an act of resistance:

Since even the sun and the waves are a syllabic script which you decipher only in times of grief and exile.

And the homeland a wall painting with successive Frankish or Slavic layers which should you attempt to restore it you go immediately to prison and give an explanation.

To a crowd of foreign Authorities through your own always. (Elytis, 1997, p. 239)

Greece can neither be anymore the cradle of Europe nor its oriental Other. It is construed outside every classification or system, on the irreducible gap of every dialectic, as the element indeed that disrupts every system. It is the unthought by the West, a wedge in the Encyclopaedic project that aspires to know and describe everything in the world.

Not by chance, Elytis develops these notions especially after the Second World War, when an incipient globalization starts to enter Greece. This globalization is perceived by him as a neocolonization, now from an economic and cultural standpoint, or, as Derrida has put it, as a globalatinization ${ }^{10}$. The term Latin is not hazardous here. Through it we can read the proximity of Elytis to Heidegger, mediated though by a nationalist bias that vulgarizes and localizes somehow the philosopher's universal intuitions. The reason why Greece is not the cradle of the West, according to Elytis, is that Classical Hellenism is but a Latin (or Renaissance) distortion, a

\footnotetext{
${ }^{10}$ For the term mondialatinisation, see Derrida (1996).
} 
closed and therefore wrong reading of a prior authentic Greekness totally absent of European culture today. The Enlightenment itself, as well as the technoscientific modernity, is the product of such a misreading or, better, of the reduction of self-productive Greekness to a readable entity. Heidegger (1998) attributes this process to the translation of the Greek aletheia, rendered by him as "unconcealment", as veritas, whereby the accent is shifted from a process of self-disclosure to a process of adequacy to a priori meanings. Elytis has long considered Latin influence as a danger to authentic Greekness, even in the realm of the alphabet. In the narration of one of his dreams, indeed, he furiously removes Latin letters from the walls of a Byzantine church in Ravenna, as he feels they are threatening its Greek nature:

I am, along with the whole procession, in front of an altar stone. Everywhere, the figure of the cross distorted, which makes me unhappy, because I shake my head in frustration. But what not only makes me unhappy but also angry are the many Latin inscriptions. However, with composure and readiness, as if everything was planned, I receive from the hands of someone who is besides me a big adz; and without hesitation, with rage, with fury, with passion, I start to hit the stone and to tear it. (Elytis, 2000, pp. 235-236)

The insistence on illegibility has to do with this. Greece is a script that, far from constituting the medium for the transmission of a message, has a value by itself. There is no teleology—a feature of European modernity—in this concept. The understanding of meaning implies the silence and the death of writing. Once the signified is transmitted, writing is not useful anymore. When meanings cannot be determined or attained, on the contrary, writing can never stop: It must continue speaking to fill the void. From this point of view, the impossibility of a closure for signifiers in Elytis's poetry makes the Greek process of self-production and reproduction, that is, of writing, not to have an origin or a telos. Illegibility determines thus a complete lack of teleological, worldly history. Following Heidegger again, we could say Greece has not Historie, that is, the narrative account of events relevant to beings, but Geschichte, the non-teleological historicity of the Being. In this way, Greece can escape again the frozen image projected by Philhellenism, not without unconsciously assuming anyway some of its features. Having become a force of constant self-reproduction unable to be hypostasized in a definite and static concept, it is not already the remote origin of Western culture whose time is gone and must be imitated by Modern Greece, but an authentic force of originality whose action has never stopped and can even be useful for reconducting the world out of the present historical impasse. In his Comment on the Axion Esti, indeed, we read the proposal first of all to avoid the closure of meaning of Greece as a conventional country that plays its reduced part in the concert of nations, and on the other hand to consider it as a self-productive and unhistoricizable sensation that can reorganize the whole world by means of its ever renewed originality:

Is Greece merely a racial unit predestined to vanish into the amalgamation of other correlate units? Is it the bearer of the values that we have been taught at the Schools and that the West appropriated (without possessing analogous sense organs)? Or perhaps is, beyond all this, a specific and unique sensation, lively and always present, a way to conceive life and to express it, which does not resemble any other and which, from this point of view, could have a new and crucial importance in the tendency of contemporary humanity to constitute itself as a global organization? (Elytis, 1995, p. 27)

The originality of Greece lies precisely in its capability of constantly reciphering itself. Every time it arrives to the supposed telos, the signified, the Greek writing finds a new origin, another signifier. The process can never end. It seems to follow the logic of the heideggerian physis, where it is the mechanism of emergence but not the final result that is underscored. 
In such a non-lineal historicity, everything is interchangeable. In one of his poems, Elytis (1997) affirms to use Minoan script in order not to be understood:

I became thousands of years old, and already I use Minoan script with such ease that the world wonders and believes in the miracle.

Fortunately they haven't managed to read me. (p. 412)

Here it is important to note that the poet prefers to stress, as many other times in his works, a preclassic stage of Ancient Greek culture. This is of course not hazardous at all, as it helps subverting the Western image of classical Greece without completely renouncing to the prestige of a genealogy on Ancient times. But, in connection to this, it is even more important to notice that the mechanism of reciphering the nation here at stake cooperates also with the resistance to the metaphorical colonization by European Philhellenism. If Classical Greece is considered to have invented, as the basis of its rationalist project, the phonetic script, that is, a script that privileges transparency by effacing its materiality in favour of the pure mental concept, Elytis tries here to reverse this historical process by taking back Greek letters to an ideographic stage. All the values associated to Greek script, as are linearity, abstractness, and rationality, are just for Elytis the values of the European technoscientific modernity, and thus foregrounded by it in its process of self-legitimization. In his poems, in fact, Elytis (1997) stresses the materiality of the Greek letters: He describes them trying to find some symbolic correspondence to their form (Elytis, 1997, p. 434) ${ }^{11}$, undermines conventional lineal reading by presenting them in alphabetical squares that can and must be read in all directions (p. 464), or includes lists of Greek words that he affirms that, regardless of their meaning, reproduce Greece wherever they are (Elytis, 1997, p. 469) ${ }^{12}$.

But, as a reciphering of the nation, the reinforcement of illegibility is of course directed to the Others. This intention seems to be eased, and fostered, by the fact that the Greek alphabet is exclusively used for writing Greek and thus by the Greeks. Resistance to Western colonial and postcolonial homogenizing influence can be symbolically represented by it. However, this reciphering must be, as we have seen, reinforced as to avoid the fixation of Greece on a frozen image or on a historical meaning. Elytis affirms to have done exactly this in order to cover the void of meaning behind the signifier "Greece":

So I very slowly took to setting words like gems to cover this country I love. Lest someone sees its beauty. Or suspect that maybe it does not exist. (Elytis, 1997, p. 424)

As an act of resistance, the weaving of signifiers not only reproduces the void in the center of signs that characterize Greece since its colonial production, but also disrupts the logophonocentrism that underlies the very

\footnotetext{
11 "Since I fell in love with these little bodies I grew thin, wasted. Asleep or awake I had nothing else in mind-just how to raise them, so one day to sleep with them. I lay in wait behind doors. I learned to catch them in air and in water. But I still don't know how to speak them.

A.-White or cyan, according to the hours and positions of the stars.

L.-Really wet. Like a pebble.

G.-The most lightweight; so your inability to pronounce it shows the degree of your barbarity.

R.-A child's and, certainly, almost always of female gender.

E.-All air. The sea breeze takes it.

U.-The most Greek letter. An urn.

S.-Weed. But the Greek must sometimes also whistle.

${ }_{12}$ Before presenting one of these lists, the poet says: "When I opened my guidebook, I understood. Neither plans nor anything, only words. But words to guide with precision to what I was looking for. So, bit by bit, turning the pages I saw the place take on form like the tear from emotion. And I in it".
} 
colonial project of the West. Illegibility implies resistance to the law, to the law of logocentrism and rationalism that defines the epistemology of modernity. That such an epistemology is also responsible for the construction of modern Greece as scission, sign, and interstice, seems not to be noticed by Elytis. After all, nobody can escape the colonial circle once he is inside. As Homi Bhabha has stated, anticolonial discourses, even the identity of colonizers and colonized, are produced in the point of contact of colonization itself (Bhabha, 1994a, pp. 50-57).

\section{Conclusions}

Though produced as a consequence of colonization itself, in postcolonial nations national literature often claims to embody the possibilities of escaping the Other's gaze where the community has been caught. This is a highly problematic process, however, since the urge to individuation needs to be articulated through institutions and discourses incorporated as a consequence of colonization itself. Our conclusion in the case of Elytis is that, attempting to create an alternative epistemological display for the nation, he ends up utilizing the very language of the West he is trying to dispel: in this case, the possibilities of Greek writing and modern poetic language as a new mode of referentiality.

\section{References}

Anderson, B. (2000). Imagined communities: Reflections on the origins and spread of nationalism. New York: Verso.

Bhabha, H. K. (1990). Narrating the nation. In H. K. Bhabha (Ed.), Nation and narration (pp. 1-7). London: Routledge.

Bhabha, H. K. (1994a). The location of culture. London: Routledge.

Bhabha, H. K. (1994b). DissemiNation: Time, narrative, and the margins of the modern nation. In H. K. Bhabha (Ed.), The location of culture (pp. 199-244). London: Routledge.

Calotychos, V. (2003). Modern Greece: A cultural poetics. Oxford: Berg.

Chrisman, L. (2004). Nationalism and postcolonial studies. In N. Lazarus (Ed.), The Cambridge companion to postcolonial literary studies (pp. 183-198). Cambridge: Cambridge University Press.

Derrida, J. (1996). Foi et savoir (Faith and knowledge). Paris: Seuil.

Du Bois, W. E. B. (2003 [1903]). The souls of black folk. New York: Barnes \& Noble.

Elytis, O. (1995). Comment on the Axion Esti (Ena anekdoto ipomnima tou Elyti yia to Axion Esti, in Greek) (edited by Y. Kechagioglou). Poiisi, 5, 27-65.

Elytis, O. (1997). The collected poems by Odysseus Elytis. (J. Carson \& N. Sarris, Trans.). Baltimore: The John Hopkins University Press.

Elytis, O. (2000). Anihta hartia (Open Papers, in Greek). Athens: Ikaros.

Fleming, K. E. (2000). Orientalism, the Balkans, and Balkan historiography. The American Historical Review, 105(4), $1218-1233$.

Goldsworthy, V. (1998). Inventing Ruritania: The imperialism of the imagination. New Haven: Yale University Press.

Gourgouris, S. (1996). Dream nation: Enlightenment, colonization, and the institution of Modern Greece. Stanford: Stanford University Press.

Heidegger, M. (1998). Parmenides. Bloomington: Indiana University Press.

Herzfeld, M. (1987). Anthropology through the looking-glass: Critical ethnography in the margins of Europe. Cambridge: Cambridge University Press.

Jusdanis, G. (1991). Belated modernity and aesthetic culture: Inventing national literature. Minneapolis: University of Minnesota. Lambropoulos, V. (1987). Literature as national institution: Studies in the politics of Modern Greek criticism. Princeton: Princeton University Press.

Mignolo, W. (2002). Rethinking the Colonial Model. In L. Hutcheon, \& M. J. Valdés (Eds.), Rethinking literary history: A dialogue on theory (pp. 155-193). Oxford: Oxford University Press. 